\title{
Erratum to: Internal waves over the shelf in the western Bay of Bengal: a case study
}

\author{
Madhu Joshi $^{1}$ - Ambarukhana Devendra Rao ${ }^{2}$ - Sachiko Mohanty ${ }^{2}$. \\ Himansu Kesari Pradhan ${ }^{2}$ - Vadlamani S. N. Murty ${ }^{3}$. \\ Koneru Venkata Siva Rama Prasad ${ }^{4}$
}

Published online: 21 November 2016

(C) Springer-Verlag Berlin Heidelberg 2016

\section{Erratum to: Ocean Dynamics}

DOI 10.1007/s10236-016-1006-3

The original version of this article unfortunately contained a mistake. The $2^{\text {nd }}$ and $4^{\text {th }}$ author names are misspelled. The corrected names are given above. Also in Fig. 10(b) $\mathrm{x}$-axis and 10(c) $\mathrm{y}$-axis were wrongly labeled. The correct Figure is shown below.

The original article was corrected.

The online version of the original article can be found at http://dx.doi.org/10.1007 /s10236-016-1006-3.

\footnotetext{
Madhu Joshi

madhu.iitd@gmail.com

1 Amity Centre for Ocean-Atmosphere Science and Technology, Amity University Gurgaon, Haryana 122413, India

2 Centre for Atmospheric Sciences, Indian Institute of Technology Delhi, New Delhi 110016, India

3 Regional Centre, CSIR-National Institute of Oceanography, Visakhapatnam 530017, India

4 Department of Meteorology and Oceanography, Andhra University, Visakhapatnam 530003, India
} 

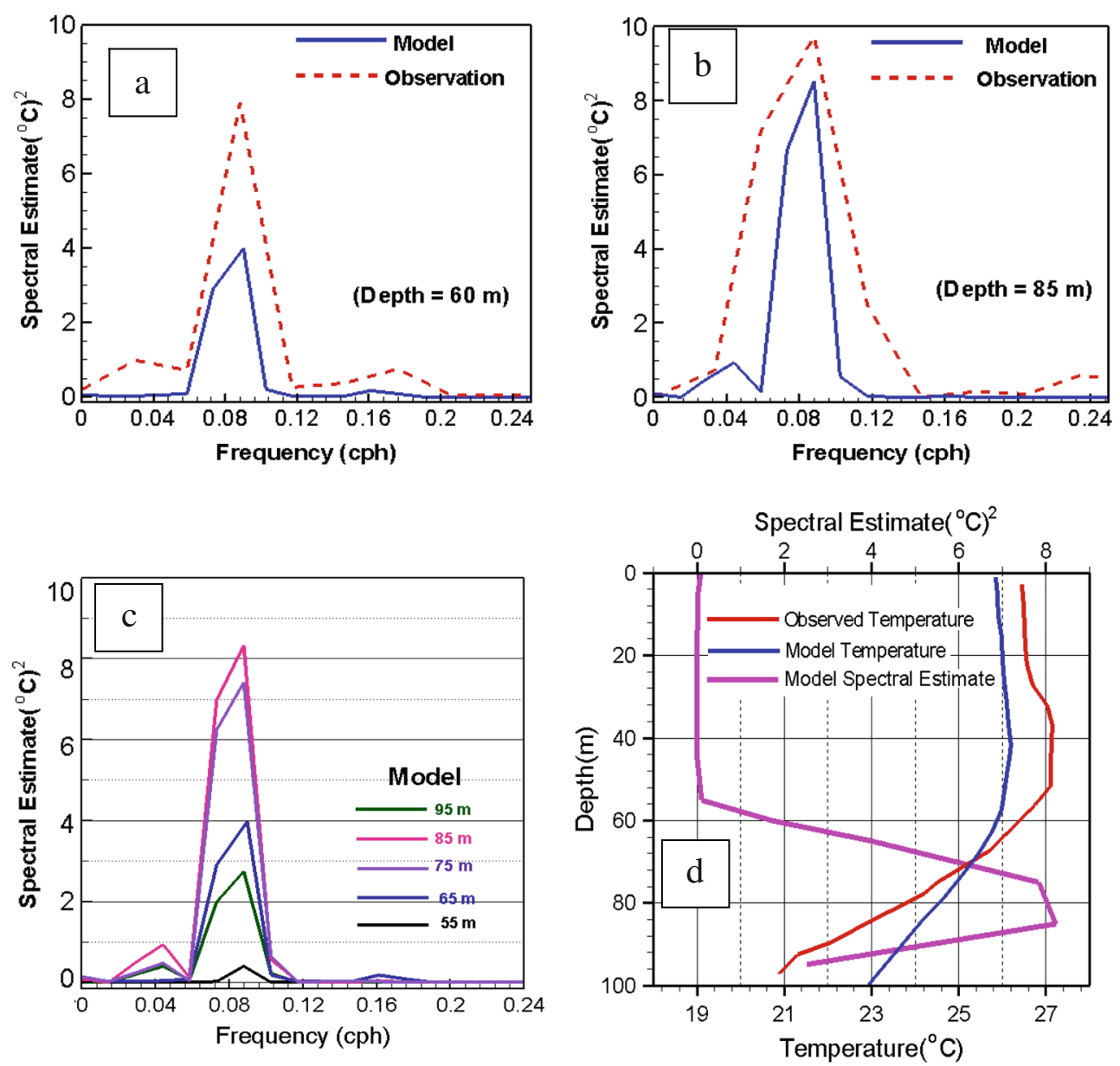

Fig. 10 Comparison of spectral estimates from observed temperature and model temperature at Stn. A during 19-21 February 2012 at depths of a $60 \mathrm{~m}$ and b $85 \mathrm{~m}$, and c model-simulated IW spectral estimate at different depths and d vertical temperature and associated energy due to semidiurnal tide 